\title{
Complete dentures with Nóbilo's sliding plates: A condylar position and electromyograph analysis
}

\author{
Rogério Favaro Pavão ${ }^{1}$, Takami Hirono Hotta ${ }^{2}$, Marcelo Palinkas ${ }^{1}$, Mariangela Salles Pereira Nassar ${ }^{1}$, \\ Selma Siéssere ${ }^{3}$, Simone Cecilio Hallak Regalo ${ }^{3 *}$, Clélia Aparecida Celino ${ }^{3}$, Marisa Semprini ${ }^{3}$, \\ César Bataglion ${ }^{1}$ \\ ${ }^{1}$ Department of Dentistry, School of Dentistry, University of São Paulo, Ribeirão Preto, Brazil \\ ${ }^{2}$ Department of Dental Materials and Prosthodontics, School of Dentistry, University of São Paulo, Ribeirão Preto, Brazil \\ ${ }^{3}$ Department of Morphology, Stomatology, and Physiology, School of Dentistry, University of São Paulo, Ribeirão Preto, Brazil \\ Email: ${ }^{*}$ schregalo@,forp.usp.br
}

Received 24 October 2011; revised 28 November 2011; accepted 2 December 2011

\begin{abstract}
Objective: This study was performed with the purpose a report clinical cases involving condylar position and Nóbilo's sliding plates. Background: Patients may present temporomandibular disorder (TMD), which is characterized by pain in masticatory muscles, temporomandibular joints and limited mandible movements. Treatment involving oral rehabilitation with the use of complete dentures with Nóbilo's sliding plates has been an alternative for the treatment of TMD. Materials and Methods: Nine patients with a history of TMD signs and symptoms (RDC/TMD)—in particular, muscular and articular pain-received pain evaluations, mandibular movement analysis, transcranial radiography and an electromyographic analysis of the masseter and temporalis muscles before and after the use of complete dentures with Nóbilo's sliding plates. Results: After treatment, the patients had reduced painful symptoms, an increase in mandibular movement and adequate electromyographic activity. The normalized EMG data were tabulated and analyzed statistically using SPSS version $\mathbf{1 7 . 0}$ for Windows (SPSS Inc., Chicago, IL, USA), and the values were compared by umpaired independent Student's $t$-test. Conclusion: The use of Nóbilo's sliding plates promoted improvements in electromyographic activity, muscular pain and mandibular movement.
\end{abstract}

Keywords: Temporomandibular Disorder; Nóbilo's Sliding Plates; Masticatory Muscle; Electromyography

\section{INTRODUCTION}

Temporomandibular dysfunction (TMD) is characterized by facial and temporomandibular joint (TMJ) pain, mas-

${ }^{*}$ Corresponding author. ticatory muscle tenderness, limited mandibular movement, joint sounds and an altered occlusal relationship [1,2].

The etiology of TMD is controversial because of the involvement of several features such as occlusion, stress, muscular hyperactivity and asymmetrical condyle position in the mandibular fossae $[3,4]$.

TMD signs and symptoms may be present in elderly patients and may also occur in complete denture wearers [5]. This is usually related to the patient's general health, head posture, chewing efficiency [1], bite force [5], and complete denture conditions [6].

The use of complete dentures for years longer than recommended usually promotes a shift in the vertical and horizontal mandibular positions; as a result, the position of the condyles in the mandibular fossae may also become altered.

\section{MATERIAL AND METHODS}

\subsection{Subjects}

Based on a standardized and complete clinical examination, nine patients with TMD symptoms were selected at the TMJ Disorders Service at Ribeirão Preto Dental School, University of São Paulo. We excluded patients who used medication or other therapies for pain control and/or who had clinical conditions in which complete dentures would be contraindicated. We included patients who used complete dentures for at least 10 years. The complete dentures had discrepancies between a retruded contact position and the habitual occlusion with a reduced vertical dimension of occlusion. The patients had a history of TMD signs and symptoms - in particular, muscular and articular pain - that was confirmed by the RDC/TMD index. The subjects were informed with regard to the research and signed a consent form that was approved by the Research Ethics Committee (process No. 2006.1.412.58.6). 


\subsection{Pain Evaluations}

Each patient was requested to indicate his or her level of pain according to a scale ranging from 0 to $3(0=$ absence of pain; 1 = light; 2 = moderate; and $3=$ severe) [7] immediately after bilateral manual palpation on the lateral pole of the condyle, masseter and the temporal muscles.

\subsection{Mandibular Movements}

Measurements of the mandibular movements were obtained using a millimeter ruler by only one operator who was previously trained to perform this procedure.

\subsection{Radiography}

Transcranial radiographs were generated using an Accurad-200 (Denar Corporation, Anaheim, CA) head holder that was adapted to an Rx device $(70 \mathrm{kVp}, 10 \mathrm{~mA}$, Spectro 70x, Dabi Atlante, Ribeirão Preto-SP, Brazil) to make templates to delimit joint spaces. Two sets of radiographs were generated for each patient, first using the old complete dentures and then using the CDSP. Referential anatomical structures such as the condyle, articular eminence and acoustic auditory meatus as visualized in the transcranial radiographs were projected and delineated on white paper. These delineated figures were placed beyond a frame (Chakley), and the condylar position was determined according the number of points in each one of the four articular spaces, at the maximum intercuspal position and in both phases of the treatment. These numbers of points were inserted in the computer program "TMJ", which showed the values of the angle and the position of the condyle dislocation. The angle provides the direction of the condyle dislocation, and the module provides the extend of this dislocation [8].

\subsection{Complete Dentures with Sliding Plates}

Maxillary and mandibular casts were mounted in a semiadjustable articulator (Gnatus, model JP 30, Ribeirão Preto, Brazil). To create the sliding plates, the occlusal aspects of the maxillary and mandibular teeth were reduced by approximately $2 \mathrm{~mm}$. The articulator was moved into the protrusive position, and the posterior balance ramps were created and placed behind the last molars to provide occlusal balance. The polymerized prostheses were adapted. Occlusal adjustments were then made on a weekly basis during the first month, and then every 15 days over the second month [9].

\subsection{Electromyography}

Surface electromyography was performed using five channels of the Myosystem-Br1 (DataHominis Ltd., Uberlândia, Minas Gerais, Brazil) with simultaneous acquisi- tion and common grounding to all channels. The surface electromyography data were collected using surface differential electrodes (two $\mathrm{Ag}-\mathrm{AgCl}$ bars, $10 \cdot 2 \cdot 1 \mathrm{~mm}$, with $10-\mathrm{mm}$ inter-electrode distance, gain of 20 , input impedance of $10 \mathrm{G} \Omega$ and a common mode rejecttion ratio of $130 \mathrm{~dB}$ ). The electromyography signals were sampled with a 12-bit AD converter board at a frequency of 2 $\mathrm{kHz}$ and band-pass filtered at $0.01-1.5 \mathrm{kHz}$. The raw sEMG data were digitally bandwidth filtered at $10-500$ $\mathrm{Hz}$, and the root mean squares (RMS) were calculated. The skin was shaved at the electrodes sites, gently abraded and cleaned with alcohol to reduce skin impedance prior to the attachment of the electrodes, which were positioned in accordance with SENIAN recommendations [10]. Surface electromyography was recorded simultaneously from the masseter and temporalis muscles on both sides. Using palpation, the muscles were located, and the electrodes were positioned bilaterally on the medial portion of the masseter muscles and on the anterior portion of the temporalis muscles with the long axes remaining parallel to the muscle fibers. During the EMG recordings, the patients were placed in a calm, quiet environment with low luminosity, sitting in an upright position with their feet on the floor, arms resting on their thighs, looking forwards, and with the Frankfort plane parallel to the floor.

\section{RESULTS}

The normalized EMG data were tabulated and analyzed statistically using SPSS version 17.0 for Windows (SPSS Inc., Chicago, IL, USA).We performed a descriptive analysis (i.e., the mean, standard deviation, and maximum and minimum values) for each variable. The values were compared using an umpaired independent Student's $t$-test.

Table 1 shows the individual pain scores $(0,1,2$ or 3$)$ that were collected with the old complete dentures (E1) and after the use of CDSP (E2).

The mean values of the mandibular movements at E1 and E2 are shown in Table 2. All of the statistically analyzed results were significant, suggesting that the use of CDSP promoted improvements in these parameters (with the exception of the buccal opening).

Table 3 shows the values of the modules and angles on the right and left sides before and after CDSP use. The statistical results were not significant $(p<0.05)$ with respect to the dislocation of the condyles.

Table 4 shows the EMG data of the clinical conditions of rest, protrusion, left lateral, right lateral and clenching in maximum voluntary contraction. At rest, the right masseter, right temporalis and left masseter muscle protrusion were not statistically significant $(p<0.05)$. 
Table 1. Pain scores $(0,1,2$ or 3$)$ that were collected during the initial phase (E1) and after the use of complete dentures with sliding plates (E2).

\begin{tabular}{|c|c|c|c|c|c|c|c|c|c|c|c|c|}
\hline \multirow{3}{*}{ Patient } & \multicolumn{4}{|c|}{ TMJ } & \multicolumn{4}{|c|}{ Masseter } & \multicolumn{4}{|c|}{ Temporalis } \\
\hline & \multicolumn{2}{|c|}{ Right } & \multicolumn{2}{|c|}{ Left } & \multicolumn{2}{|c|}{ Right } & \multicolumn{2}{|c|}{ Left } & \multicolumn{2}{|c|}{ Right } & \multicolumn{2}{|c|}{ Left } \\
\hline & E1 & E2 & E1 & E2 & E1 & E2 & E1 & E2 & E1 & E2 & E1 & E2 \\
\hline 1 & 2 & 0 & 3 & 1 & 0 & 0 & 0 & 0 & 3 & 0 & 2 & 1 \\
\hline 2 & 2 & 1 & 1 & 0 & 0 & 0 & 0 & 0 & 0 & 0 & 0 & 0 \\
\hline 3 & 1 & 0 & 2 & 0 & 0 & 0 & 0 & 0 & 0 & 0 & 1 & 0 \\
\hline 4 & 1 & 0 & 2 & 1 & 0 & 0 & 0 & 0 & 0 & 0 & 1 & 0 \\
\hline 5 & 0 & 0 & 3 & 0 & 0 & 0 & 0 & 0 & 0 & 0 & 0 & 0 \\
\hline 6 & 2 & 1 & 3 & 1 & 1 & 0 & 2 & 0 & 0 & 0 & 3 & 0 \\
\hline 7 & 2 & 0 & 2 & 0 & 1 & 0 & 1 & 0 & 2 & 0 & 2 & 0 \\
\hline 8 & 3 & 1 & 2 & 0 & 2 & 1 & 1 & 1 & 3 & 1 & 3 & 0 \\
\hline 9 & 1 & 0 & 1 & 0 & 2 & 0 & 2 & 0 & 0 & 0 & 0 & 0 \\
\hline
\end{tabular}

Table 2. Mean values (in millimeters) of the mandibular movement before and after treatment.

\begin{tabular}{ccccccccc}
\hline \multirow{2}{*}{ Patient } & \multicolumn{2}{c}{ Mouth opening } & \multicolumn{2}{c}{ Right laterality } & \multicolumn{2}{c}{ Left laterality } & \multicolumn{2}{c}{ Protrusion } \\
\cline { 2 - 9 } & E1 & E2 & E1 & E2 & E1 & E2 & E1 & E2 \\
\hline 1 & 50.0 & 52.0 & 3.0 & 9.0 & 1.0 & 9.0 & 3.0 & 9.0 \\
2 & 42.5 & 43.0 & 6.0 & 7.0 & 5.5 & 7.0 & 4.5 & 7.5 \\
3 & 46.0 & 49.0 & 10.0 & 10.0 & 6.0 & 7.0 & 3.0 & 7.0 \\
4 & 54.0 & 55.0 & 4.0 & 8.0 & 5.0 & 6.0 & 4.5 & 7.5 \\
5 & 29.0 & 53.0 & 3.5 & 6.0 & 5.0 & 6.0 & 4.0 & 9.0 \\
6 & 45.0 & 41.0 & 4.0 & 9.0 & 5.0 & 8.0 & 7.5 & 7.0 \\
7 & 58.0 & 63.0 & 3.0 & 6.0 & 3.0 & 5.0 & 3.0 & 4.0 \\
8 & 41.5 & 48.5 & 7.0 & 8.0 & 5.0 & 6.0 & 5.5 & 6.5 \\
9 & 54.0 & 57.0 & 6.0 & 9.0 & 5.0 & 8.0 & 5.0 & 5.5 \\
Mean & 46.6 & 51.3 & 5.1 & 8.0 & 4.5 & 6.9 & 4.4 & 7.0 \\
\hline
\end{tabular}

\section{DISCUSSION}

To arrive at an accurate diagnosis and to prepare a treatment plan, a detailed clinical examination and history must be performed, and this must include the use of a complementary exam such as a study of casts that were set on a semi-adjustable articulator, radiography of the temporomandibular joints and an electromyographic analysis [11-13]. Based on this evaluation, several types of treatment may be indicated, including interocclusal splints, [14] physiotherapeutic resources, psychological therapy [15], therapeutic prostheses [16] and complete dentures with sliding plates [1].

The aim of this clinical study was to evaluate the condylar position and clinical evaluations of TMD patients. Therefore, CDSP was the chosen modality of treatment due to its neuromuscular deprogramming effect [1-9] and the improved horizontal and vertical maxillomandibular relationships.

The data related to condylar position, module and angle were subjected to a statistical analysis comparing E1 and E2, and no significant differences were observed. However, the numeric mean values that were obtained in the E2 measurements suggested that the condyles were more balanced in the mandibular fossae than in their position in E1.

After the use of these prostheses, the patients reported greater comfort and improved esthetic appearance. The patients also reported that they could chew more effectively while wearing the CDSP than with their old dentures. 
Table 3. Module (M) and angle (A) values before and after CDSP on the right and left sides.

\begin{tabular}{|c|c|c|c|c|c|}
\hline \multirow{2}{*}{ Patient } & Module & Right & Right & Left & Left \\
\hline & Angle & Before & After & Before & After \\
\hline \multirow{2}{*}{1} & $\mathrm{M}$ & 0.9683 & 1.0825 & 0.9469 & 0.7373 \\
\hline & A & 23.56 & 1.35 & 13.13 & 30.20 \\
\hline \multirow{2}{*}{2} & $\mathrm{M}$ & 1.1381 & 1.0273 & 0.6912 & 0.5525 \\
\hline & A & 4.90 & 11.19 & 15.21 & 18.74 \\
\hline \multirow{2}{*}{3} & M & 1.1823 & 0.9166 & 0.9037 & 0.9724 \\
\hline & A & 1.15 & 11.73 & 12.30 & 1.31 \\
\hline \multirow{2}{*}{4} & M & 1.1944 & 1.1372 & 0.4764 & 0.5780 \\
\hline & A & 8.80 & 9.99 & 23.25 & 21.60 \\
\hline \multirow{2}{*}{5} & M & 1.0766 & 1.1525 & 1.0657 & 1.0117 \\
\hline & A & 5.98 & 9.58 & 6.34 & 8.32 \\
\hline \multirow{2}{*}{6} & $\mathrm{M}$ & 1.0034 & 0.8488 & 0.9695 & 0.9895 \\
\hline & A & 20.67 & 17.13 & 17.63 & 18.14 \\
\hline \multirow{2}{*}{7} & $\mathrm{M}$ & 0.3848 & 0.7934 & 0.9546 & 0.9071 \\
\hline & A & 18.17 & 11.25 & 16.25 & 5.32 \\
\hline \multirow{2}{*}{8} & M & 0.4931 & 0.3455 & 0.9030 & 0.9850 \\
\hline & A & 5.38 & 1.82 & 16.26 & 0.00 \\
\hline \multirow{2}{*}{9} & M & 0.4472 & 0.8242 & 0.4700 & 1.0260 \\
\hline & A & 19.87 & 10.76 & 21.67 & 0.00 \\
\hline \multirow{2}{*}{ Mean } & M & 0.8764 & 0.9031 & 0.8201 & 0.8621 \\
\hline & A & 12.05 & 9.42 & 15.78 & 11.51 \\
\hline
\end{tabular}

Zuccolotto et al. [1] previously analyzed the electromyographic activity of the masseter and temporal muscles and observed that the painful symptoms were significantly reduced, and this is consistent with the results of our study.

In the resting position, the EMG values with the CDSP (E2) were higher than those with the old prosthesis (E1), and this differs from the data that were reported by Silva et al. [17]. It is likely that these results are associated with the structural changes conferred by inserting the new prostheses, which increased the occlusal vertical dimen- sion by an average of $5.0 \mathrm{~mm}$. Because the muscular activities were evaluated three months after the insertion of the CDSP, the masseter and temporal muscles may not be used to measure the new occlusal vertical dimension. In contrast with an earlier study [1], the one-year follow-up showed reduced electromyographic activity in the resting position after the use of CDSP.
Table 4. Surface EMG (in microvolts/second) normalized (at mean and standard deviation) of the right masseter (RM), left masseter (LM), right temporal (RT) and left temporal (LT) muscles during rest, protrusion, right and left laterality and maximum clenching.

\begin{tabular}{|c|c|c|c|c|}
\hline $\begin{array}{l}\text { Clinical } \\
\text { Condition }\end{array}$ & Muscles & E1 & E2 & Significance \\
\hline \multirow{4}{*}{ Rest } & $\mathrm{RM}$ & $0.12 \pm 0.01$ & $0.22 \pm 0.02$ & \multirow{4}{*}{ * } \\
\hline & LM & $0.15 \pm 0.03$ & $0.24 \pm 0.04$ & \\
\hline & RT & $0.15 \pm 0.02$ & $0.33 \pm 0.07$ & \\
\hline & LT & $0.25 \pm 0.05$ & $0.30 \pm 0.04$ & \\
\hline \multirow{4}{*}{ Protrusion } & $\mathrm{RM}$ & $0.60 \pm 0.19$ & $0.30 \pm 0.04$ & \multirow{4}{*}{ * } \\
\hline & LM & $0.72 \pm 0.17$ & $0.34 \pm 0.04$ & \\
\hline & RT & $0.20 \pm 0.40$ & $0.36 \pm 0.09$ & \\
\hline & LT & $0.29 \pm 0.05$ & $0.34 \pm 0.06$ & \\
\hline \multirow{4}{*}{$\begin{array}{c}\text { Right } \\
\text { Laterality }\end{array}$} & $\mathrm{RM}$ & $0.26 \pm 0.10$ & $0.27 \pm 0.04$ & \\
\hline & LM & $0.45 \pm 0.07$ & $0.30 \pm 0.05$ & \\
\hline & RT & $0.20 \pm 0.04$ & $0.36 \pm 0.09$ & \\
\hline & LT & $0.28 \pm 0.05$ & $0.32 \pm 0.05$ & \\
\hline \multirow{4}{*}{$\begin{array}{c}\text { Left } \\
\text { Laterality }\end{array}$} & $\mathrm{RM}$ & $0.37 \pm 0.12$ & $0.27 \pm 0.04$ & \\
\hline & LM & $0.35 \pm 0.11$ & $0.30 \pm 0.04$ & \\
\hline & RT & $0.19 \pm 0.04$ & $0.30 \pm 0.05$ & \\
\hline & LT & $0.65 \pm 0.13$ & $0.50 \pm 0.10$ & \\
\hline \multirow{4}{*}{$\begin{array}{l}\text { Maximum } \\
\text { Clenching }\end{array}$} & $\mathrm{RM}$ & $1.16 \pm 0.18$ & $1.28 \pm 0.15$ & \\
\hline & LM & $1.22 \pm 0.18$ & $1.30 \pm 0.16$ & \\
\hline & RT & $0.85 \pm 0.11$ & $1.05 \pm 0.09$ & \\
\hline & LT & $0.99 \pm 0.17$ & $1.01 \pm 0.17$ & \\
\hline
\end{tabular}

${ }^{*}$ Significant $(p<0.05)$.

The electromyographic activity during clenching in maximum voluntary contraction was higher with the CDSP. This finding may be associated with the stabilization and retention of the new denture base, balanced occlusion, a reduction in painful symptoms and the re-establishment of the occlusion vertical dimension, which is consistent with a report by Hotta et al. [18].

In the mandibular protrusion, the electromyographic activity of the masseter muscles was greater than the activity that was verified in the temporal muscles, whereas with CDSP the values were similar. As mentioned above, this result is likely related to the biomechanical properties that were conferred by the insertion of the new prosthesis.

When wearers of complete dentures perform lateral movements, bilateral activation of the muscles occurs due to the occlusal contacts on both sides (i.e., working 
and balancing), which allow the stabilization of the prosthesis. In the presence of canine guidance without occlusal interferences on the working and balancing sides, decreased electromyographic activity may be measured, as reported by Landulpho et al. [19]. It should be noted that with the CDSP, the electromyographic activity of the temporal muscle was greater than that of the masseter muscle, and this is explained by the functional action of these muscles.

\section{CONCLUSION}

We conclude that in the present study, the use of complete dentures with Nóbilo's sliding plates was effective in reducing painful symptoms, re-establishing the occlusion vertical dimension and muscular function promoting the freedom of mandibular movements, and allowing a more physiological position of the mandible.

\section{ACKNOWLEDGEMENTS}

This study was supported by the Foundation for Research Support of São Paulo (FAPESP).

\section{REFERENCES}

[1] Zuccolotto, M.C.C., Vitti, M., Nóbilo, K.A., Regalo, S.C.H., Siéssere, S. and Bataglion, C. (2007) Electromyographic evaluation of masseter and anterior temporalis muscles in rest position of edentulous patients with temporomandibular disorders, before and after using complete dentures with sliding plates. Gerodontology, 24, 105-110. doi:10.1111/j.1741-2358.2007.00152.x

[2] Hotta, P.T., Hotta, T.H., Bataglion, C., Bataglion, S.A., De Souza Coronatto, E.A., Siéssere, S. and Regalo, S.C. (2010) EMG analysis after laser acupuncture in patients with temporomandibular dysfunction (TMD). Implications for practice. Complementary Therapies in Clinical Practice, 16, 158-160. doi:10.1016/j.ctcp.2010.01.002

[3] Rigon, M., Pereira, L.M., Bortoluzzi, M.C., et al. (2011) Arthroscopy for temporomandibular disorders. Cochrane Database of Systematic Reviews, 11, 5.

[4] Troeltzsch, M., Troeltzsch, M., Cronin, R.J., et al. (2011) Prevalence and association of headaches, temporomandibular joint disorders, and occlusal interferences. Journal of Prosthetic Dentistry, 105, 410-417. doi:10.1016/S0022-3913(11)60084-X

[5] Hotta, P.T., Hotta, T.H., Bataglion, C., et al. (2008) Bite force in temporomandibular dysfunction (TMD) and healthy complete denture wearers. Brazilian Dental Journal, 19, 354-357. doi:10.1590/S0103-64402008000400012

[6] Dervis, E. (2004) Changes in temporomandibular disorders after treatment with new complete dentures. Journal of Oral Rehabilitation, 31, 320-326.

doi:10.1046/j.1365-2842.2003.01245.x
[7] Nowlin, T.P. and Nowlin, J.H. (1995) Examination and occlusal analysis of the masticatory system. Dental Clinics of North America, 39, 379-401.

[8] Bataglion, C., Hotta, T.H., Borges, M.A.G., et al. (2003) Avaliações clínica, electromiográfica e do posicionamento condilar de paciente tratado com placa oclusal: Caso clínico. Stoma, 14, 17-21.

[9] Zuccolotto, M.C.C., Nóbilo, K.A., Nunes, L.J., et al. (1999) Sliding plates on complete dentures as a treatment of temporomandibular disorder: A case report. Journal of Craniomandibular Practice, 17, 289-292.

[10] Hermens, H.J., Freriks, B., Merletti, R., et al. (1999) European recommendations for surface electromyography, roessingh research and development B.V., results of SENIAN project. Enschede, Netherlands.

[11] Di Paolo C., D'Ambrosio, F., Panti, F., et al. (2006) The condyle-fossa relationship in temporomandibular disorders. Considerations on the pathogenetic role of the disc. Minerva Stomatol, 55, 409-422.

[12] Reis, A.C., Hotta, T.H., Ferreira-Jerônymo, R.R., et al. (2000) Ear symptomatology and occlusal factors: A clinical report. Journal of Prosthetic Dentistry, 83, 21-24. doi:10.1016/S0022-3913(00)70084-9

[13] Manfredini, D., Cocilovo, F., Favero, L., et al. (2011) Surface electromyography of jaw muscles and kinesiographic recordings: Diagnostic accuracy for myofascial pain. Journal of Oral Rehabilitation, 38, 791-799. doi:10.1111/j.1365-2842.2011.02218.x

[14] De Félicio, C.M., Freitas, R.L. and Bataglion, C. (2007) The effects of orofacial myofunctional therapy combined with an occlusal splint on signs and symptoms in a man with TMD-hypermobility: Case study. International Journal of Orofacial Mycology, 33, 21-29.

[15] Gross, S.M. and Vacchiano, R.B. (1973) Personality correlates of patients with temporomandibular pain dysfunction. Journal of Prosthetic Dentistry, 30, 326-329. doi:10.1016/0022-3913(73)90191-1

[16] Ingawalé, S. and Goswami, T. (2009) Temporomandibular joint: Disorders, treatments, and biomechanics. Annals of Biomedical Engineering, 37, 976-996. doi:10.1007/s10439-009-9659-4

[17] Silva, M.A., Issa, J.P., Vitti, M., et al. (2006) Electromyographical analysis of the masseter muscle in dentulous and partially toothless patients with temporomandibular joint disorders. Electromyography and Clinical Neurophysiology, 46, 263-268.

[18] Hotta, T.H., Vicente, M.F., Dos Reis, A.C., et al. (2003) Combination therapies in the treatment of temporomandibular disorders: A clinical report. Journal of Prosthetic Dentistry, 89, 536-539. doi:10.1016/S0022-3913(03)00077-5

[19] Landulpho, A.B., Silva, W.A., Silva, F.A., et al. (2004) Electromyographic evaluation of masseter and anterior temporalis muscles in patients with temporomandibular disorders following interocclusal appliance treatment. Journal of Oral Rehabilitation, 31, 95-98. 